\title{
Comparing Surface Height Used in NCAR Climate Model with That Observed by ICEsat: Effects on Skin Temperature Simulation
}

\author{
Menglin Jin \\ Department of Meteorology, San Jose State University, CA 95192-0140, USA \\ Correspondence should be addressed to Menglin Jin, jin@met.sjsu.edu
}

Received 29 July 2009; Accepted 25 October 2009

Recommended by Klaus Dethloff

\begin{abstract}
This paper tries to identify one of the reasons for the poor land skin temperature simulated by a climate model over Greenland. It first compares ICEsat surface height measurements over Greenland with those used by the model and reveals that the surface height of Greenland prescribed in the National Center for Atmospheric Research (NCAR) Community Climate System Model/Community Land Model version 3 (CCSM/CLM3) differs greatly from the satellite measurements from National Aeronautics and Space Administration (NASA) ICEsat at edges and central glacier regions. This deficiency, in part, leads to underestimated skin temperatures at coastal regions - the areas where significant ice sheet melt is observed. Furthermore, sensitivity studies reveal that surface skin temperature simulations of Greenland would be significantly improved if the more accurate surface height is used. The problem of the height used in current global climate model is mainly due to the fact that the model has to use coarse grid size, and within one grid, land surface height has high heterogeneity. How to assign a proper surface height for each model grid and meanwhile adequately present the high heterogeneity of land surface is a great challenge in current model development.
\end{abstract}

Copyright (C) 2009 Menglin Jin. This is an open access article distributed under the Creative Commons Attribution License, which permits unrestricted use, distribution, and reproduction in any medium, provided the original work is properly cited.

\section{Introduction}

The temperature of Greenland has been increasing more rapidly than that of any other land or oceanic surface of comparable size [1-3]. This leads to large effects on surface ice melt. In particular, the surface height, which is a dynamical mass balance largely between snowfall accumulation in Winter and snowmelt in Spring, varies as function of surface temperature. However, the consequences of such height variations are not addressed in global climate models. Recently, the National Aeronautics and Space Administration (NASA) ICEsat platform measured fine resolution surface height data [4], which can be used in validating global climate models (GCMs). This paper examines how well this surface height is represented in the National Center for Atmospheric Research (NCAR) Community Climate System Model/Community Land Model version 3 (CCSM/CLM3), and how important this variable is for Greenland surface skin temperature simulation.

Surface height and surface skin temperature are closely related to each other $[5,6]$. Skin temperature of the polar regions affects surface energy balance and thus ice sheet melt. Antarctica and Greenland are covered by ice sheets exceeding 3000 meters in thickness, containing an amount of ice equivalent to about $78 \%$ of the fresh water on Earth. On sufficiently warm days, surface temperature can become warm enough to contribute to melting of the ice sheet at its edges. Such melting can reduce land surface albedo, increase surface temperature, and thus more snow and ice sheet melts, that is, it is a positive feedback.

Climate models, for example, CCSM/CLM3, generally set $\mathrm{H}$ as a prescribed parameter. Its values are derived from some global digital elevation map which is smoothed enough to eliminate the model's dynamic instabilities that would occur for too rough a low boundary. However, as this paper shows, such smoothing will introduce large and possibly unacceptable errors in local skin temperature simulations. The differences in $\mathrm{H}$ over Greenland between ICEsat and CCSM/CLM3 are up to 600-1000 m. Large differences are also seen between the skin temperature observed from the National Aeronautics and Space Administration (NASA) Moderate Resolution Imaging Spectroradiometer MODIS 
and that simulated the model. A simple modeling sensitivity study is used in this paper to suggest that much of the difference between the observed and the modeled temperatures may be accounted for by the difference between observed and model assumed elevation. Section 2 of this paper describes the datasets and background information used for our analysis. Section 3 discusses the results and is followed by a section of final discussion and remarks (Section 4).

\section{Data}

ICEsat Surface Height Data. ICEsat-observed surface height for Greenland is used to evaluate this parameter in the NCAR model. The ICEsat mission, part of NASA's Earth Observing System (EOS) Mission, was launched in January 2003. The Geoscience Laser Altimeter System (GLAS) on ICEsat measured ice sheet elevations, together with the changes in elevation through time and approximate sea ice thickness. The surface height is provided at a $1 \mathrm{~km} \times 1 \mathrm{~km}$ horizontal resolution. We used the measurements for July, 2003.

MODIS Land Surface Temperature. The MODIS instrument is carried on NASA's Terra satellite, launched in December, 1999, and NASA's Aqua satellite, launched in May, 2002. Skin temperatures were measured in 7 solar and 3 thermal spectral bands at 10:30 LT and 22:30 LT daily (Terra) and 13:30 LT and 1:30 LT (Aqua). Each pixel has a 1-km resolution at the nadir [7]. The measurements used in this study have been scaled up to a 5-km resolution and averaged to monthly values. Only the measured values with quality flags attesting to the absence of clouds are used.

NCAR CCSM/CLM3. The NCAR community land surface model version 3 (CLM3) is an advanced land surface model designed to be coupled with global or regional atmosphere models to simulate land surface energy balance, hydrological process, and the effects of vegetation [8]. CCSM via its atmosphere component Community Atmosphere Model (CAM3) provides atmospheric forcing to CLM3 including air temperature, downward shortwave and longwave radiations, rainfall, relative humidity, and wind at each model timestep, and CLM3 calculates the important biophysical processes of the land surface. Figure 1 presents the July means from the CCSM3.0/CLM3.0 1990 control simulation for years 445-449. These years are a subsection of the simulation analyzed by Dickinson et al. [8].

\section{Results}

3.1. Observed versus Measured Skin Temperature. Figure 1(a) shows that the lowest observed skin temperature occurs at the center of Greenland but extends to the southern mountainous regions around $65^{\circ} \mathrm{N}$. Over these permanently glaciated regions, the skin temperature is lower than $260 \mathrm{~K}$. By contrast, near the edge of Greenland, the July skin temperature can be as high as $290 \mathrm{~K}$.

Significant differences are observed between the CCSM/ CLM3 modeled skin temperature simulations (Figure 1(b))

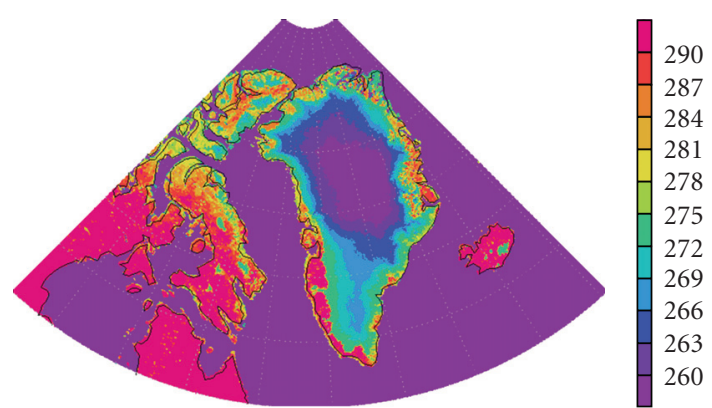

(a)

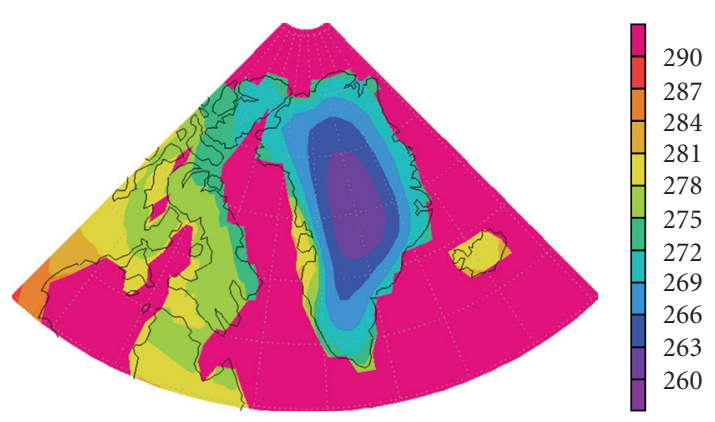

(b)

FIGURE 1: (a) MODIS observed monthly mean land surface skin temperature starting for July, 2003; (b) CCSM/CLM3 simulated 5year average of July ground surface temperature.

and satellite observations (Figure 1(a)). First, CCSM/CLM3 overestimates the surface skin temperature in the central glacier regions by at least several degrees - the observed skin temperature is lower than $260 \mathrm{~K}$, but the modeled values are above $260 \mathrm{~K}$. Second, the modeled temperatures do not show the cold center in the southern part of Greenland (around $65^{\circ} \mathrm{N}$ ). Furthermore, the modeled skin temperature at the edges is about $10 \mathrm{~K}$ cooler than that observed. Such deficiencies in skin temperature simulation may be largely due to the inaccuracy of surface height used in the model as demonstrated in the next section.

3.2. Observed versus Model Surface Height $(H)$. In general, observed $\mathrm{H}$ over Greenland is low at the edges and increases to the center (Figure 2(a)). $\mathrm{H}$ is smooth at the central part above $3000 \mathrm{~m}$ around $70^{\circ} \mathrm{N}, 40^{\circ} \mathrm{W}$, while $\mathrm{H}$ close to the edges is near to sea surface. In addition to the central peak in $\mathrm{H}$ around $75^{\circ} \mathrm{N}$, the southern region has a peak up to $2500 \mathrm{~m}$ within $60-65^{\circ} \mathrm{N}, 40-45^{\circ} \mathrm{W}$. Considering the size of Greenland, the large changes of height (from 0 to $3000+\mathrm{m}$ ) mean a dramatic surface height change over that region.

The standard deviation reveals the high variability of $\mathrm{H}$ in Greenland at its edges (Figure 2(b)), where the standard deviation from values averaged to the model resolution is mostly as high as $500 \mathrm{~m}$ to $600 \mathrm{~m}$. By contrast, the inner part of Greenland is relatively flat, with a standard deviation of height less than $100 \mathrm{~m}$.

The surface height $\mathrm{H}$ of CCSM/CLM3 is shown in Figure 2(c). The most notable discrepancies between 


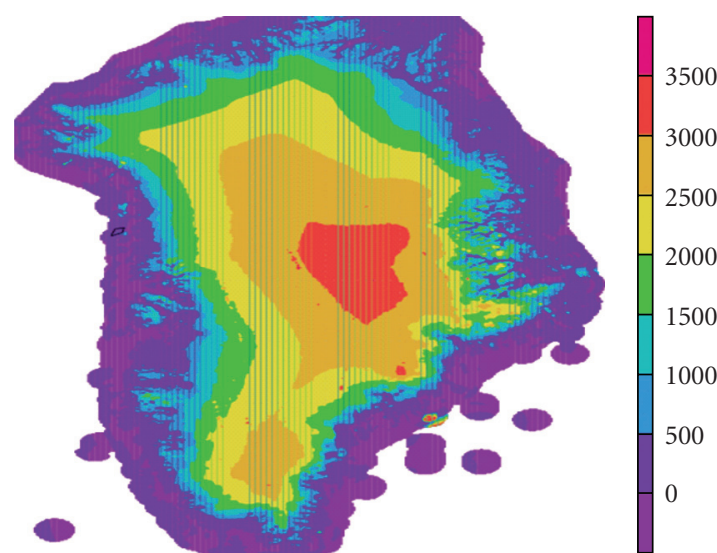

(a)

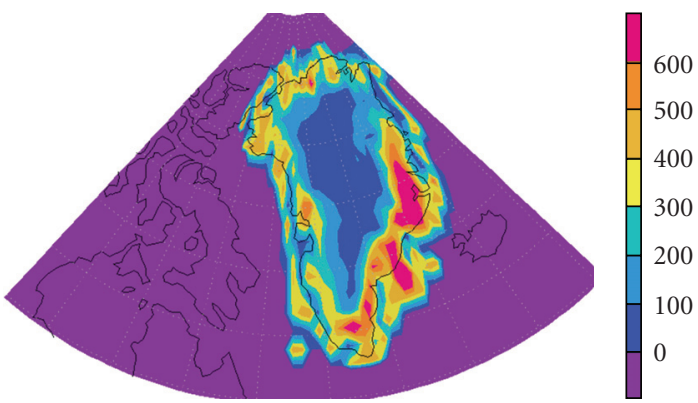

(b)

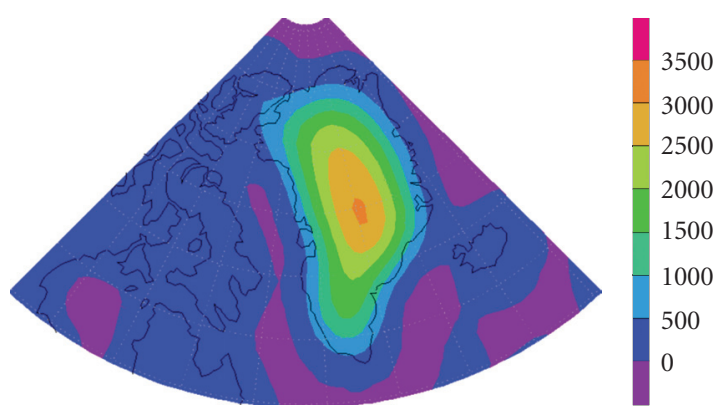

(c)

FIGURE 2: (a) ICEsat observed surface height of Greenland at a spatial resolution of $1 \mathrm{~km}$; (b) ICEsat standard deviation of surface height; and (c) surface height in CAM3/CLM3 at T85 resolution.

the satellite observations (Figure 2(a)) and model $\mathrm{H}$ (Figure 2(c)) are as follows:

(1) The model has only one location in the central part above $2500 \mathrm{~m}$, but the observed peak in the southern region in Figure 2(a) is missing in the model dataset.

(2) The edges have smaller variability in $H$ than that in the observed, and in particular, the abrupt changes in $\mathrm{H}$ are not well represented in the model.

(3) Much of central Greenland is lower in the model than in the observations.

Further comparison along $80^{\circ} \mathrm{N}$ (Figure 3 ) reveals that although the shape of model $\mathrm{H}$ along $80^{\circ} \mathrm{N}$ is quite similar to

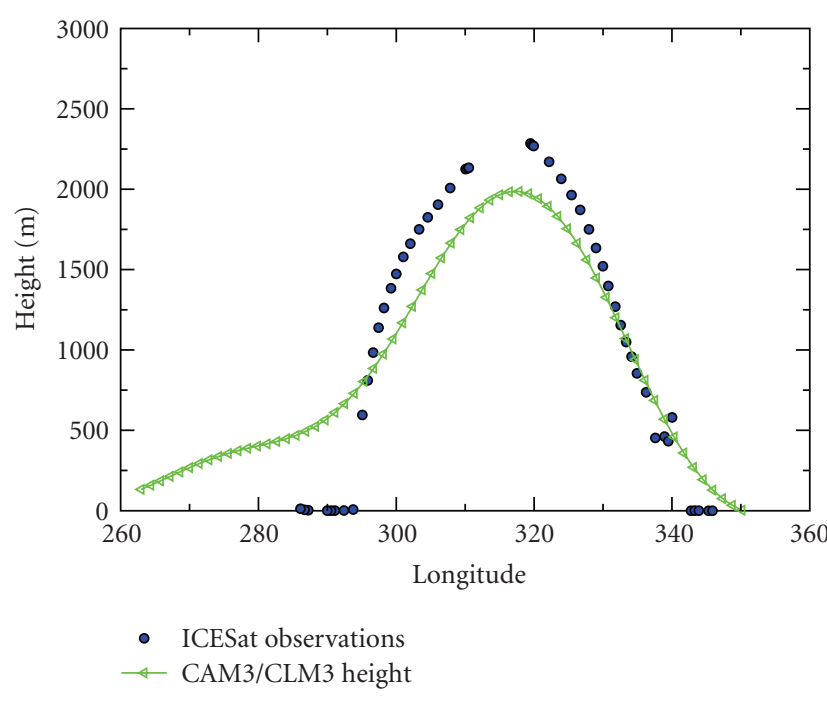

FIGURE 3: Comparison of surface height from ICEsat measurements with the CAM3/CLM3 surface height along the $80^{\circ} \mathrm{N}$ transect across Greenland.

the ICEsat observations, the absolute value of height has large differences. In particular, at the edges, most of the model values are higher than observations but elsewhere the modelused $\mathrm{H}$ is lower than ICESAT-based $\mathrm{H}$. In many regions, such differences can be up to $1000 \mathrm{~m}$. Similar differences are also observed for $70^{\circ} \mathrm{N}$ (not shown). How such errors in surface height affect the simulation of skin temperature in the model is the question we will address in subsection below.

3.3. Model Sensitivity to Greenland Surface Height. To examine the importance of Greenland surface height in model simulations, we conducted a control simulation and a sensitivity simulation where Greenland surface height in the model is replaced by ICEsat observation. Both experiments use the offline (uncoupled from the atmospheric model) CLM3.5 and the NCEP reanalysis as atmospheric forcing [9]. Model timestep is 20 seconds and horizontal resolution is T42. Note that in offline CLM3.5, surface pressure and air temperature change with the height according to lapse rate of $0.9^{\circ} \mathrm{C} / 100 \mathrm{~m}$. Such design is based on the modelICEsat difference revealed in Figure 2 where model surface is mostly lower than observation by an average of $500 \mathrm{~m}$. Of course, such a design may only provide an upper boundary on how sensitive the model may be due to the extreme change in surface height. The monthly mean surface ground temperature (namely, skin temperature for snow surface) is used to assess the impact of the change in surface height.

Figure 4 shows that the offline CLM3.5 modeled Greenland ground temperature (namely, skin temperature over ice-covered surface) decreases about $2.5 \mathrm{~K}$ with the increase of surface height. At the edges the current model's surface height is higher than the observations (see the color in Figure 4, also Figure 3); therefore, reducing surface height there would lead to an increase of skin temperature, up to $1{ }^{\circ} \mathrm{C}$ in offline CLM3.5. Note that the presented model output is a 17-year climatology of July, August, and September 


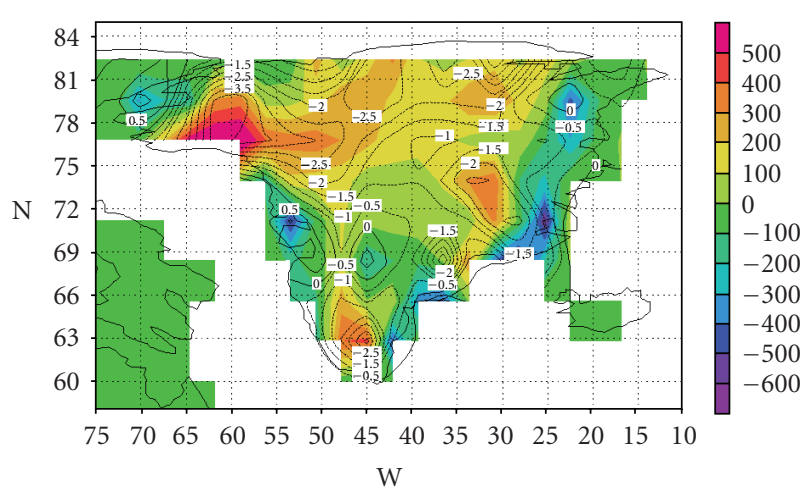

FIgURE 4: Sensitivity of offline CLM3.5 simulated Greenland ground temperature (TG) to the surface height (experiment case minus control run, T42 resolution). The 17 -year, monthly averaged TG in the experiment case is using ICEsat-observed Greenland surface height. The fields are June, July, and August averages. The color bar is surface height difference $(\mathrm{m})$ and the contour is temperature difference.

averaged skin temperature. Instantaneous values during sunny daytime can be much higher and so enhance the snow melt. Such an improvement in ground/skin temperature simulation would allow a better simulation of Summer snowmelt at the edges. Further, in the middle of Greenland, the skin temperatures would be lowered by using the higher surface heights that are observed. Consequently, regional temperatures gradient will be increased in model which could possibly improve regional wind simulation.

\section{Discussion}

Current determination of Greenland surface height in NCAR CCSM is partly responsible for an inaccurate simulation of skin temperature and could be improved by assimilating the ICEsat observations into the model. As a result, skin temperature simulations would be improved evidently because of the close relation between surface temperature and surface height. A possibly significant further contribution to skin temperature is the large spatial variability of the terrain (Figure 2(b)) that modifies surface energy balance, for example, by reducing the effective albedo and emissivity via the so-called "slope effect"-multiple scattering via the hills (e.g., $[10,11])$.

The coupled model should may have a stronger sensitivity to the land surface height than the offline land surface model because many height-related physical and dynamical processes cannot be addressed in an offline land surface model. However, because skin temperature itself is a combined result of many processes, the coupled model may provide a smaller reduction of temperature with altitude change than used in the offline model. Current challenge in fully use of satellite high-resolution height data in a coupled model is that how to represent surface elevation heterogeneity in a model grid, which in general is $30-100 \mathrm{~km}$. This could be one extreme important research topic in polar land surface.
The problem of the height used in current global climate model is mainly due to the fact that a global model has to use coarse grid size to avoid the dynamic instabilities (Gibbs effect) for rapidly varying surface. For regions where within one grid land surface height has high heterogeneity, how to assign a proper surface height for each model grid and meanwhile adequately present the high heterogeneity of land surface is a research topic.

\section{Acknowledgments}

This work was funded by NSF GEO/ATM/LARS/CLD Grant no. 060928-9145. The author would like to express sincere appreciation to Drs. Weili Wang and Jay Zwally of the NASA Goddard Space Flight Center for providing us ICEsat surface height observations.

\section{References}

[1] W. Abdalati, W. Krabill, E. Frederick, et al., "Outlet glacier and margin elevation changes: near-coastal thinning of the Greenland ice sheet," Journal of Geophysical Research, vol. 106, no. D24, pp. 33729-33741, 2001.

[2] J. E. Dibb and M. Fahnestock, "Snow accumulation, surface height change, and firn densification at Summit, Greenland: insights from 2 years of in situ observation," Journal of Geophysical Research, vol. 109, no. 24, Article ID D24113, 8 pages, 2004.

[3] M. Jin, "Analysis of land skin temperature using AVHRR observations," Bulletin of the American Meteorological Society, vol. 85, no. 4, pp. 587-600, 2004.

[4] J. P. DiMarzio, A. C. Brenner, H. A. Fricker, B. E. Schutz, C. A. Shuman, and H. J. Zwally, "Digital Elevation Models of the Antarctic and Greenland Ice Sheets From ICESat," EOS, C51B0276, 2005.

[5] J. R. Garatt, The Atmospheric Boundary Layer, Cambridge University Press, Cambridge, UK, 1992.

[6] C. A. Shuman, D. H. Bromwich, J. Kipfstuhl, and M. Schwager, "Multiyear accumulation and temperature history near the North Greenland Ice Core Project site, north central Greenland," Journal of Geophysical Research, vol. 106, no. D24, pp. 33853-33866, 2001.

[7] Z. Wan and J. Dozier, "A generalized split-window algorithm for retrieving land-surface temperature from space," IEEE Transactions on Geoscience and Remote Sensing, vol. 34, no. 4, pp. 892-905, 1996.

[8] R. E. Dickinson, K. W. Oleson, G. Bonan, et al., "The Community Land Model and its climate statistics as a component of the Community Climate System Model," Journal of Climate, vol. 19, no. 11, pp. 2302-2324, 2006.

[9] G. B. Bonan, K. W. Oleson, M. Vertenstein, et al., "The land surface climatology of the community land model coupled to the NCAR community climate model," Journal of Climate, vol. 15, no. 22, pp. 3123-3149, 2002.

[10] Y. Chen, A. Hall, and K. N. Liou, "Application of threedimensional solar radiative transfer to mountains," Journal of Geophysical Research, vol. 111, no. 21, Article ID D21111, 3 pages, 2006.

[11] M. Jin and S. Liang, "An improved land surface emissivity parameter for land surface models using global remote sensing observations," Journal of Climate, vol. 19, no. 12, pp. 28672881, 2006. 

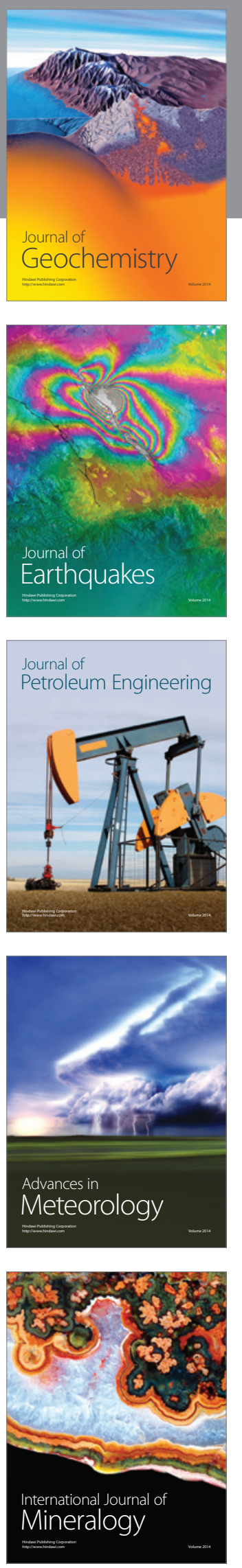
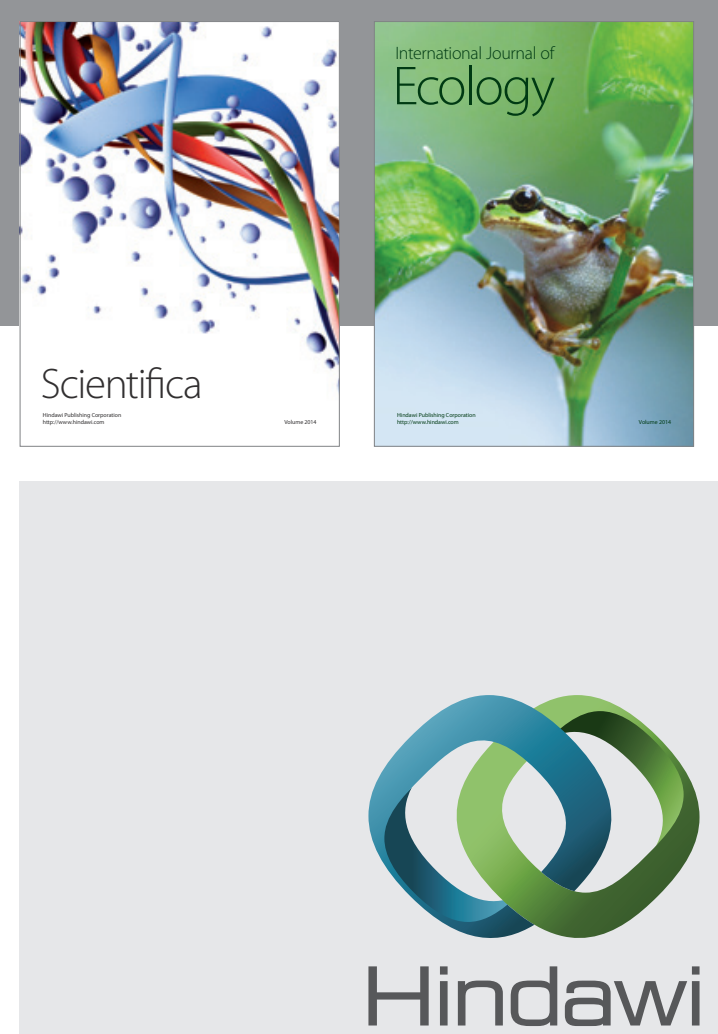

Submit your manuscripts at http://www.hindawi.com
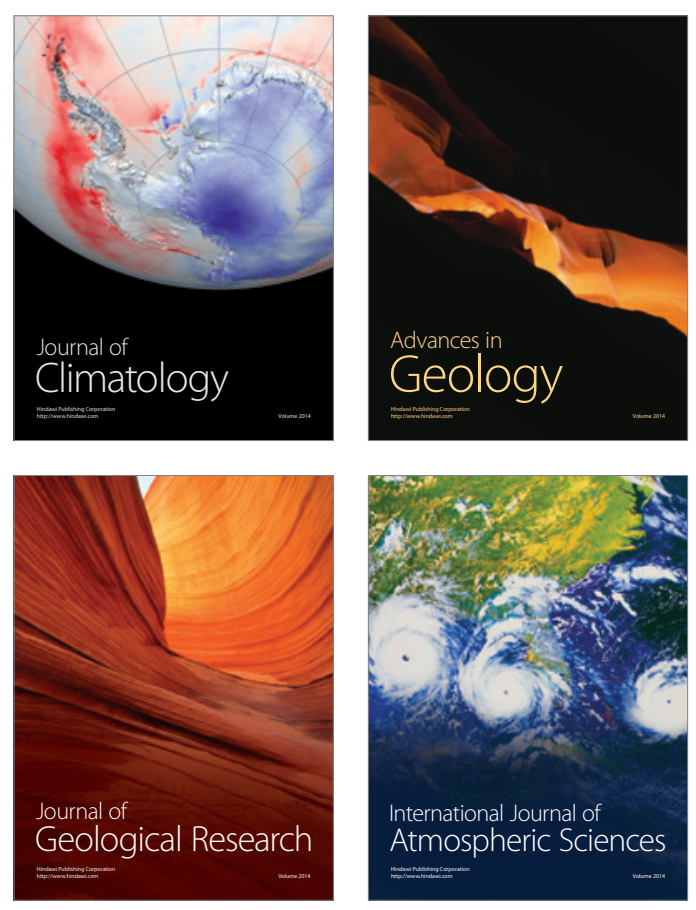
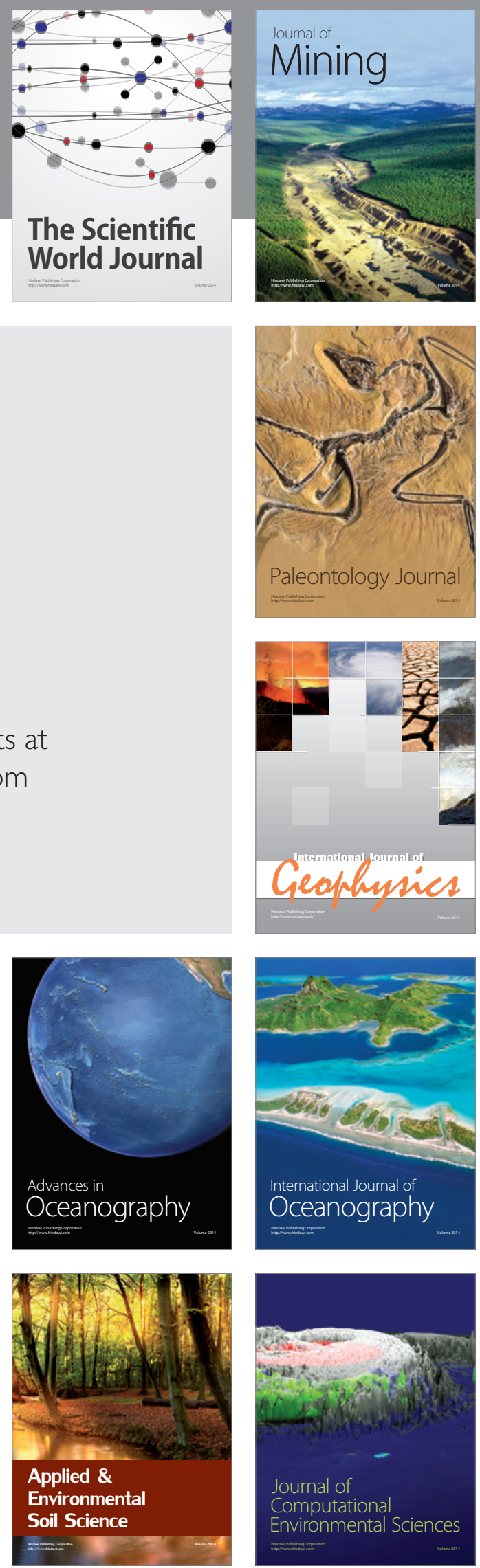